\title{
Online Video Advertisement Avoidance: Can Interactivity Help?
}

Dildar Hussain, ESC Rennes School of Business, France Hélène Lasage, ESC Rennes School of Business, France

\begin{abstract}
The objective of this research is to explain the factors contributing toward consumers' online video advertisement (OVA) avoidance behavior. Empirical data from 207 online consumers in France supports the hypotheses concerning the effect of relevance of contents, perceived authenticity and interactivity of OVAs. The findings suggest that consumers avoid OVAs by using ad blocker software due to irrelevant advertisement contents, lack of perceived authenticity of advertisement contents and most importantly due to the lack of interactivity. We conclude the study by offering some suggestions for reducing consumers' avoidance of OVAs by increasing interactivity.
\end{abstract}

Keywords: Online Consumer Behavior; Online Video Advertisements; Content Relevance; Content Trustworthiness; Interactivity; Intrusiveness

\section{INTRODUCTION}

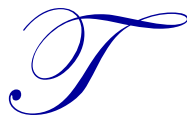

he global advertising expenditures can be split into online advertising, television \& radio, printed advertising and other media (outdoor displays for instance). Online advertisement is one most important advertising media in terms of its growth and future potential (Damratoski et al., 2011). To be more specific, online media advertising represents around $20 \%$ of the total advertising spending worldwide. However, in terms of growth and future prospects, online advertising is much more important as compared to the other methods of advertising. Its growth is much higher than the other traditional media, it was around $15 \%$ between 2006 and 2007, compared to $2.2 \%$ for TV advertising, $-1.4 \%$ for radio and $-1.8 \%$ for the print advertising. In 2012, the growth rate of global online advertising expenditures stays above $16 \%$, and the total amount spent on online advertisements was above $€ 76$ billion (GroupM, 2013). The spending on online advertising in Europe was above $€ 24$ billion in 2012 which accounts for more than a quarter of the total advertising budget (Knapp, 2013).

The number of Internet users in France has continuously grown over the past three decades; people are spending more and more time on the web. With the development of coverage networks, it has now become easier to navigate on the Internet from anyplace, anywhere, anytime. The number of Internet users in the world has doubled in five years; it increased from 18\% of the world population in 2006 to 35\% of the world population in 2011. Moreover, the time spent watching video online has also increased and more than $85 \%$ of the total online audience watched online videos in 2011. Observing this tendency, marketers understood the challenge of communicating on the web by developing specific advertisement formats in order to target as many people as possible. Indeed, it has been observed that the spending in France on online advertising from 2010 to 2011 has increased by about 11\%, and has reached $€ 2.5$ billion. Internet advertising expenses represented $14.4 \%$ of the total advertising expenses in France which means that it is still below the global proportion of spending on online advertising i.e., 20\%. In other words, French market still have a huge potential for growth in online advertising.

The Web2.0 or "Interactive Web" is nowadays presented as a major evolution and as the foundation of a new political, economic, technological and social era. The Web2.0 is the result of an adaptation strategy of communication and cultural industries; it has given a new form of freedom generated by interpersonal exchanges. The different evolutions in the field of the digital communication have allowed both consumers and the firms more flexibility. Additionally, the shift of consumers from the traditional communication channels (e.g., TV) to the 
Internet has made it imperative for companies to increase their focus on the electronic channels (Damratoski et al., 2011).

An online video advertisement (OVA) is a "video content distributed via the Internet to be streamed or downloaded onto compatible devices such as computers and mobile phones" (IteractiveAdertisingBureau, 2013). The very basic from of online video advertisement is running TV ads on the Internet. However, increasingly, the marketers adapt TV ads or create video ads exclusively for running them online. Mainly, OVAs insertion is concentrated on the start, middle or the end of a video clip (Wang et al., 2008) or it can be independently presented to the consumers. AVOs can be delivered in a variety of other methods. OVAs can be divided into the following types based on their delivery modes:

- $\quad$ Embedded Video: These video advertisements are embedded within a webpage and can be triggered by a user's click on the banner.

- $\quad$ Subsite: An OVA opens in a separate browser and starts playing automatically generally when the user closes the original webpage.

- In-Text Video: These advertisements are delivered when a user rolls over a highlighted or underlined word in the text of a webpage.

- $\quad$ Email Video: Video advertisements can be embedded within an email and can be delivered to the user upon opening of the email text or on clicking at the banner within the email.

- In-Game Video: These advertisements are delivered during the game is being loaded or in between the different levels of the game.

An OVA delivered through any of the above delivery modes can be categorized in one of the following two categories:

- Linear Video Advertisements: These are typically 15-30 second slots run on the start, middle, or the end of a video. Generally these advertisements cannot be fast forwarded.

- Interactive Video Advertisements: These video advertisements allow a variety of user interactions. The user can click for further information; locate a store, find contact details, or sign up for a newsletter through these video advertisements. The users can also choose which advertisement to watch and when to watch. Sometimes, interactive video advertisements also have an option to skip the advertisement. Interactive video advertisements usually are mix of video content, animation, text, or static images and interactive elements.

The Web2.0 can prove to be an incredible tool for companies by making it easier to reach out a wide consumer base. On the other hand, many companies nowadays face real challenges in reaching to the right target segments because the consumers are often bombarded with online and offline advertisements and hence they start avoiding almost everything that seems to have advertising contents. Restriction notices on doors and postal inboxes, spam filters for email, and ad blockers for online advertisements are examples of consumers' extensive avoidance. OVA avoidance can be illustrated by an action done by consumers in order to avoid the advertisement; it can be done by closing the advertisement window, or skipping the advertisement, as it is sometimes possible in some players to directly have access to the desired contents. Now, electronic avoidance is also possible through the use of Internet technologies; consumers who really feel irritated can install specific software to stop advertisements and to delete pop-up. The use of ad blockers software is the most widely used electronic method of avoiding online advertisements. This study aims at explaining the key factors contributing toward the OVA avoidance behavior of the consumers. The article proposes and empirically tests factors triggering the use of electronic method of avoiding OVAs by installing ad blockers.

Section two presents a brief literature review and development of hypotheses. In section three, we describe the methodology for this study and the fourth section offers findings and discussion. Some theoretical and practical implications of the study are also discussed in the fourth section. The last section (the fifth section) concludes the article by discussing limitations of this study and by presenting some directions for the future research. 


\section{THEORY AND HYPOTHESES}

Advertisement avoidance is a crucial issue for advertisers. If we take the example of TV advertisements, around $80 \%$ of TV commercials are avoided. With this avoidance phenomenon, it appeared plausible for companies to use other media i.e., the Internet. The challenge of companies communicating on the web is now to avoid this existing situation with TV commercials. Taking into account the billions of euro spent every year by advertisers, it is necessary to find strategies which can reduce the consumers' zapping, skipping, or clicking past advertisements and which can increase the exposure of consumers to OVAs. Varkatsas and Ambler (1999) suggest that positive emotion creation is a key success factor to make consumers watch a video advertisement. Mittal (1995) defines several emotions created by advertisement; enjoyable, offensive, informative, deceptive, annoying and useful. He shows that an advertisement can create both positive and negative incentives at the same time. Hence in order to understand how it is possible to produce positive emotions for advertisement, it is important first to define the determinants of advertising avoidance. Several studies have been conducted on this topic, some have directly attempted to explore these factors in the traditional advertisement settings (e.g., Mehta, 2000; Homer, 2006). One of the major factors of advertisement avoidance is the lack of trust in advertising. The mistrust is illustrated by the fact that the function of advertising is perceived more as a manipulative approach than an informative one. Trust is an important determinant of the quality of relationship between a customer and a brand (Morgan \& Hunt, 1994). Trust is an even more serious problem for the Internet as a means of communication. Therefore, lack of trust may have a positive relationship with advertisement avoidance in general and OVA avoidance in particular.

Cho and Choen (2004) outline a conceptual model explaining the determinants of online advertisement avoidance. They present three main factors behind online advertising avoidance which are the interruption of tasks, meaning that the consumers cannot freely achieve their goal on the Internet without being disturbed by advertisements. The second factor is negative past experience of the consumer. The third factor is clutter on the web which refers to an excessive amount of advertising associated with useless messages. Some advertisements appear in an intrusive way and in a too frequent way and it may reduce the positive emotions of the consumers. The intrusiveness depends on the placement of the advertisement, the moment when it appears, and the way the advertisement interacts with the Internet user. Consumers like controlling what they want to see. They want to decide when and how they will receive the advertisement message. The fact that consumers are now overexposed to advertisement messages is a real threat for advertisers and it can also lead to a negative perception of the communicating brand. Consumers' participation in marketing process of companies is not a new concept (Von Hippel, 1986). However, a more recent concept of user generated contents (UGC) emerged in 2005. It is related to a set of media communication where the contents are mostly created or directly influenced by the final users. This phenomenon is a foundation for the audiovisual production means emerged in the recent years based on the development of new technologies (Cooke \& Buckley, 2008). Some examples of UGC are wikis, podcasting, blogs and interactive videos. Therefore, interactive advertisements may bear a relatively lower risk of advertisement avoidance and may also lead to creation of positive emotions among the consumers.

Another factor mentioned by Cho and Cheon (2004) is the effect of past negative experience, this can be caused by the wrong messages addressed to the wrong target audience for instance. Mittal (1995) identifies the possibility of creating positive emotions or incentives if the provided contents are enjoyable. It means that the online advertising is supposed to give positive experience through an entertaining message that is relevant to the consumers' interests. Speck and Elliot (1997) also suggest that the consumers avoid advertisements due to many reasons which could be cognitive, behavioral, or mechanical. Cognitive avoidance of advertising is the fact that consumers make the choice to avoid it by focusing on the contents they want to see. Hence advertisement contacts

have a direct impact on the advertisement avoidance behavior of the consumers. Based on the above discussion, we develop the following three hypotheses for this study.

H1: OVA avoidance is triggered by the perceived lack of authenticity of the advertisement contents.

H2: OVA avoidance is triggered by the perceived irrelevance of the advertisement contents.

H3: OVA avoidance can be avoided by interactive video advertisements. 


\section{METHODOLOGY}

\subsection{Data Collection}

The primary data was collected from online consumers in France. As the objective of the study is to investigate the general OVA avoidance behavior of the consumers; therefore, the respondents were not selected from a specific segment. We used convenience sampling and a contact list of online consumers in France available with a local advertising consultancy firm served as the sampling frame. A total of 650 consumers were contacted to fill the questionnaire available on Google Docs. Only those consumers were requested to fill the questionnaire who had been exposed to OVAs in the past. The respondents were requested to answer the questions keeping in view their general perception about the OVAs not for some specific brand, product, or business sector. The respondents were requested to express their general perception about OVAs on all types of websites excluding gaming websites. After three reminders, we received 207 filled questionnaires accounting to a $31.85 \%$ response rate. 58\% of the respondents were male and $42 \%$ were female. Half of the respondents were in the age bracket of $18-24,41.5 \%$ of the respondents were in the 25-35 years old category. The rest of the respondents were more than 35 years old. Some of the responses were non-usable due to item non response and 196 responses out of 207 were used for analysis and testing hypotheses. 85 respondents used ad blocker while 111 did not use ad blocker.

\subsection{Measurement}

Our dependent variable is the OVA avoidance behavior (AVD) and the usage of ad blocker software is used as a proxy for AVD. The respondents were asked a dichotomous question whether they use ad blocker software or not. 0 refers to not using the software while 1 refers to using ad blocker software.

We have three independent or predictor variables in the model i.e., perceived lack of authenticity of advertisement contents (AUT), perceived lack of relevance of advertisement contents (REL), and perception of lack of interactivity of most of the OVAs (INT). Adapted from the previous research on the subject (Li et al., 2002; Cho $\&$ Cheon, 2004), AUT was measured using a three-item five-point scale and the respondents were asked questions about exaggeration of facts, originality and clarity of information in OVAs. Cronbach's alpha for AUT is 0.827. REL was also measured by a three-item five-point scale and the respondents were asked about interestingness, usefulness, and relevance of OVA contents. Cronbach's alpha for this variable is 0.798 . The last predictor variable i.e., INT was measured using a two-item fine-point scale and the respondents were asked about interactivity and intrusiveness of OVAs. Cronbach's alpha for INT is 0.903. Age (AGE) and gender (GEN) are included in the model as control variables. AGE is a categorical measure dividing respondents in three groups i.e., 18-24, 25-35, and above 35. Gender is a dichotomous measure referring 1 to female and 2 to male.

\section{FINDINGS AND DISCUSSION} below.

We use logistics regression analysis to test the hypotheses. Regression results are appended in Table 1

Table 1: Logistic Regression Results

\begin{tabular}{|l|c|c|c|}
\hline \multicolumn{1}{|c|}{ Predictor } & B & SE B & $\mathbf{e}^{\mathbf{B}}$ \\
\hline AUT & $0.498^{* *}$ & 0.298 & 0.608 \\
\hline REL & $0.327^{* *}$ & 0.206 & 0.721 \\
\hline INT & $0.751^{* *}$ & 0.243 & 1.102 \\
\hline AGE & $-0.345^{*}$ & 0.241 & 1.412 \\
\hline GEN & -0.522 & 0.307 & 0.593 \\
\hline Constant & 1.494 & & 196 \\
\hline N & & 0.238 & \\
\hline Cox \& Snell R & & 0.308 & \\
\hline Negelkerke $\mathrm{R}^{2}$ & & & \\
\hline
\end{tabular}

$* \mathrm{p}<0.05 ; * * \mathrm{p}<0.01 ; \mathrm{e}^{\mathrm{B}}=$ exponentiated $\mathrm{B}$

As presented in the regression results (Table 1), all three hypotheses (H1, H2, \& $\mathrm{H} 3$ ) proposed in this study are supported by the data analysis. The OVA avoidance behavior of consumers (measured by the usage of ad Copyright by author(s); CC-BY 
blocker software) is triggered by the perceived lack of authenticity of advertisement contents and perceived irrelevance of advertisement contents. Perceived lack of interactivity also contributes toward avoidance of OVAs.

Contrary to the previous research findings (Rojas-Méndez et al., 2009), our data do not support the effect of gender on the use of electronic means of advertisement avoidance. On the other hand, we find a weak support for the effect of age on OVA avoidance behavior. Younger consumers are more likely to use electronic methods (e.g., ad blockers) for avoiding OVAs. This may also be linked to the level of skills in using technology. Young consumers, most of the times, are considered to be more proficient in using technology and the latest tools.

It is a big challenge for advertisers nowadays to reach out to the right customers with the right message. Commercial advertising managers have to find powerful solutions in order to make sure that their delivered message will reach properly to their target audience. In order to reduce the advertisement avoidance tendency, it is imperative that the firms try to overcome the factors that trigger OVA avoidance. In addition, issues with OVAs could also result in severe negative influence on the consumers and hence ultimately may result in serious damages to the brand and to the business.

This study suggests that the firms need to increase relevance of the contents of their advertisements especially of OVAs. In other words, targeting the right customers is very important otherwise, it may result in a general advertisement avoidance behavior among the consumers. On the other hand, advertisements having little relevant contents may also appear too intrusive to the consumers ( $\mathrm{Li}$ et al., 2002). Therefore, the perceived relevance may have a double effect on the advertisement avoidance behavior of the consumers.

Perceived authenticity of the advertisement contents also plays an important role in advertisement avoidance behavior. Trustworthiness of online communication remains one of the biggest concerns for advertisers. However, repeated transactions or repeated positive interaction with the consumer may decrease the problem of perceived lack of authenticity of the contents (Shmatikov \& Talcott, 2005; Jøsang et al., 2007; Wang \& Vassileva, 2007). Additionally, authenticity of OVA contents can be at least partly increased by avoiding information exaggeration and by including only "verifiable" facts and claims.

Another important problem with OVAs is the lack of interactivity and the perception of intrusiveness. Most of the consumers who use ad blockers perceive that OVAs are generally quite low on interactivity and that most of the OVAs are quite intrusive. Intrusiveness of OVAs can not only result in triggering OVA avoidance behavior but it may also turn the consumer off in the very beginning. This, somehow, creates the very first negative impression in the minds of the consumers and may also affect the other elements of the advertisement. Perception of intrusiveness may also amplify the effect of the perceived lack of relevance and the perceived lack of trustworthiness. Increasing interactivity of the OVAs may also help advertisers deal with avoidance problem (Sundar \& Kim, 2005). So, it is important to increase interactivity of OVAs in order to tackle with consumers' advertisement avoidance behavior. Interactivity of OVAs can be increased in several ways. Links for further information, skip option, and OVA length choice are few examples of increasing interactivity of OVAs. Interactive OVAs not only would reduce OVA avoidance but will also provide additional opportunities to the consumers to explore further information and hence may result in enhancing consumers' interaction with the advertiser. On the other hand, it may also help reduce the perception of intrusiveness.

This study makes an important contribution to the existing body of literature on advertising in general and to online consumer behavior in particular. OVAs are an important mode of communication to the consumer in today's business environment and none of the previous studies investigates the factors that induce AVO avoidance behavior among the online consumers. Hence this study is the first of its kind to investigate this emerging yet under researched area and presents some empirical evidence from France in order to enhance our understanding of online consumer behavior. This study also has implications for the practitioners. The findings will help them better utilize their advertising budgets by focus on the key issues that trigger advertisement avoidance behavior. The findings suggest that, consistent to the suggestions offered by the previous research, increasing relevance and trustworthiness of OVA contents may result in reducing advertisement avoidance behavior. The findings suggest that imposing OVAs may have very little positive impact on the consumers and hence may result in advertisement avoidance behavior due to lack of interactivity. 


\section{CONCLUSION}

This study provides some insights of the factors triggering the use of ad blockers to avoid OVAs and the findings suggest that OVA avoidance can be reduced by increasing consumers' perceived levels of content relevance, content authenticity, and OVA interactivity. The findings concerning relevance and content authenticity are consistent to the previous research findings presented in the traditional advertising context. The findings suggest that it is very important for the advertisers to target the right consumers with the right type of OVAs. OVAs lacking in relevance of contents and trustworthiness in general and interactivity in particular may influence the consumers negatively. Hence, it is important to increase the level of interactivity in OVAs in order to reduce the intrusiveness and ultimately OVAs avoidance.

\subsection{Limitations}

The findings of this study are subject to several important limitations. First, the sample size is not very large and is skewed towards young population and hence may not be representative of the entire online customer population. Second, there could be several other factors, not included in this study, contributing towards the customers' advertisement avoidance behavior. We also do not take into account cultural, environmental and individual customer related factors (educational background, profession, level of computer knowledge, etc.) which may have influence on consumers' use of ad blocker. We also do not test the effects of different usages of OVAs, their delivery mode, and different types of websites for example, search engines, company websites, online stores, video streaming websites, were also not taken into consideration. Hence it is difficult to determine whether the findings regarding the usage of ad blocker software are relevant for all type of users and usages. However, this may provide some important guidelines and foundations for the future research in this field of continuously growing importance.

\subsection{Directions for the Future Research}

The future research may investigate the issue with larger and more representative samples and by including additional factors as mentioned above. Privacy concern of users is another important area and it would be interesting to investigate the effect of users' privacy concerns on their online advertisement avoidance behavior. The effect of concern for privacy could be particularly high for the users with lower level of Internet skills (Chatterjee \& McGinnis, 2010). The future research may also look into different types of OVAs and in different business sectors. Findings from other markets different to the French market in terms of market development, technology acceptance and cultural behavior could also deepen our understanding of consumers' behavior about OVAs.

\section{AUTHOR INFORMATION}

Dildar Hussain, $\mathrm{PhD}$ is an assistant professor of marketing and the program manager for MSc in International Luxury and Brand Management at ESC Rennes School of Business, France. His research interests include franchising, strategic networks, entrepreneurship, and luxury and brand management. E-mail: dildar.hussain@esc$\underline{\text { rennes.fr }}$ (Corresponding author)

Hélène Lasage was an MSc in International Marketing student at ESC Rennes School of Business, France. Her research interests include web marketing, online consumer behavior, and brand management.

\section{REFERENCES}

1. Chatterjee, P., \& McGinnis, J. (2010). Customized online promotions: Moderating effect of promotion type on deal value, perceived fairness, and purchase intent. Journal of Applied Business Research, 26(4), 13-20.

2. Cho, C., \& Cheon, H. (2004). Why do people avoid advertising on the Internet? Journal of Advertising, 33(4), 89-97.

3. Cooke, M., \& Buckley, N. (2008). Web 2.0, social networks and the future of market research. International Journal of Market Research, 50(2), 267-292. 
4. Damratoski, K., Field, A., Mizell, K., \& Budden, M. (2011). An investigation into alternative television viewership habits of college students. Journal of Applied Business Research, 27(1), 69-76.

5. GroupM. (2013). Global Internet ad spend hit \$99bn in 2012, almost 20\% of total investment. Retrieved May 10, 2013, from http://www.wpp.com/wpp/press/2013/mar/27/global-internet-ad-spend-hit-99bn-in2012/

6. Homer, P. (2006). Relationships among ad-induced affect, beliefs, and attitudes: Another look. Journal of Advertising, 35(1), 35-51.

7. IteractiveAdertisingBureau. (2013). IAB Ireland. Retreived September 01, 2013, from http://iabireland.ie/display-council/jargon-buster/

8. Jøsang, A., Ismail, R., \& Boyd, C. (2007). A survey of trust and reputation systems for online service provision. Decision Support Systems, 43(2), 618-644.

9. Knapp, D. (2013). IAB AdEx Benchmark 2012. Retrieved September 01, 2013, from http://www.iabeurope.eu/files/8813/7363/8652/Interact_2013_ADEX_Presentation_FINAL.pdf

10. Li, H., Edwards, S., \& Lee, J. (2002). Measuring the intrusiveness of advertisements: Scale development and validation. Journal of Advertising, 31(2), 37-47.

11. Mehta, A. (2000). Advertising attitudes and advertising effectiveness. Journal of Advertising Research, 40(3), 67-71.

12. Mittal, B. (1995). A comparative analysis of four scales of consumer involvement. Psychology \& Marketing, 12(7), 663-682.

13. Morgan, R., \& Hunt, S. (1994). The commitment-trust theory of relationship marketing. The Journal of Marketing, 58(3), 20-38.

14. Rojas-Méndez, J., Davies, G., \& Madran, C. (2009). Universal differences in advertising avoidance behavior: A cross-cultural study. Journal of Business Research, 62(10), 947-954.

15. Shmatikov, V., \& Talcott, C. (2005). Reputation-based trust management. Journal of Computer Security, 13(1), 167-190.

16. Speck, P., \& Elliott, M. (1997). Predictors of advertising avoidance in print and broadcast media. Journal of Advertising, 26(3), 61-76.

17. Sundar, S., \& Kim, J. (2005). Interactivity and persuasion: Influencing attitudes with information and involvement. Journal of Interactive Advertising, 5(2), 6-29.

18. Vakratsas, D., \& Ambler, T. (1999). How advertising works: What do we really know? The Journal of Marketing, 63(1), 26-43.

19. Von Hippel, E. (1986). Lead users: A source of novel product concepts. Management Science, 32(7), 791805 .

20. Wang, J., Fang, Y., \& Lu, H. (2008). Online video advertising based on user's attention relavancy computing. Paper presented at the 2008 IEEE International Conference on Multimedia and Expo.

21. Wang, Y., \& Vassileva, J. (2007). A review on trust and reputation for web service selection. Paper presented at the Distributed Computing Systems Workshops, ICDCSW'07. 
NOTES 